\title{
Optical fibre chemical sensor for trace vanadium(V) determination based on newly synthesized palm based fatty hydroxamic acid immobilized in polyvinyl chloride membrane
}

\begin{abstract}
Fatty hydroxamic acid (FHA) immobilized in polyvinyl chloride (PVC) has been studied as a sensor element of an optical fibre chemical sensor for $\mathrm{V}(\mathrm{V})$. By using this instrument, $\mathrm{V}(\mathrm{V})$ in solution has been determined in the $\log$ concentration range of $0-2.5$ (i.e. $1.0-300 \mathrm{mg} / \mathrm{L}$ ). The detection limit was $1.0 \mathrm{mg} / \mathrm{L}$. The relative standard deviation (R.S.D.) of the method for the reproducibility study at $\mathrm{V}(\mathrm{V})$ concentration of $200 \mathrm{mg} / \mathrm{L}$ and $300 \mathrm{mg} / \mathrm{L}$ were calculated to be $2.9 \%$ and $2.0 \%$, respectively. Interference from foreign ions was also studied at 1:1 mole ratio of $\mathrm{V}(\mathrm{V})$ :foreign ions. It was found that, $\mathrm{Fe}(\mathrm{III})$ ion interfered most in the determination of vanadium(V). Excellent agreement with ICP-AES method was achieved when the proposed method was applied towards determination of $\mathrm{V}(\mathrm{V})$.
\end{abstract}

Keyword: Optical fibre, PVC membrane, V(V) sensor, Fatty hydroxamic acid 